\title{
The Influence of Parental Perceptions of Media Influences on Co- viewing/using Media and Instructive Mediation with Younger Children Gabriella Sandstig*
}

Department of Journalism, University of Gothenburg, Gothenburg, Sweden

\begin{abstract}
This study aims to fertilize research on parental mediation with the importance of parents' positive media attitudes. In this study Swedish parents' perceptions of media influences and their consequences on their child/ children aged 2-5 years are in focus. Data from a cross-sectional population survey performed by the Swedish Media Councilin 2010 covered a representative sample of children, aged 2-5 years in total 1195 . The results are that the parents have both positive as well as negative perceptions of media influences andthe factor analysis of the parents perceptions, depending on the media type, fall out in two to three dimensions-negative aspects of media influences, positive aspects of media influences and mixed positive and negative outcomes. In line with previous research it is very common to co-view/use media. But on the contrary to previous research it is even more common to discuss the content and experience with their 2-5 year old child/children. The more perceptions of positive media influence, the more often we co-view/use media with our child/children aged 2-5 years old. The opposite goes for the more we perceive negative media influences. However the same pattern only complies for instructive mediation when it comes to discussing films and TV and not for discussion games or content or experiences on the web.
\end{abstract}

Keywords: Parental perceptions; Media; Mediation; Influence; Coviewing

\section{Introduction}

Parents attitudes towards media content and influences of the media, rather than state censorship or the media habits of the parents', has shown to be the most important factor to protect children from harmful media influences [1]. During the second half of the $20^{\text {th }}$ century especially the negative attitudes towards violent media content and the protection of children from the harmful effects of the television like development of aggressive behavior was in focus [2]. Recent research has also shown that the media, even though they are not the main cause, can affect child obesity, deficiencies in the child's social and cognitive skills and other aspects of children's health from both older and newer forms of media [3].

But even though most of the research conducted is on the negative influences of the media on children, the positive aspects are starting to get noticed. A reason for the renewed interest and especially the interest in younger children (0-6 years) is that even the youngest due to a vastly changing media landscape with new users and usage of media, no longer merely are receivers of media content but participants and actors in their media consumption [4-7]. These contemporary changes indicate that family communication patterns are transforming, which puts further emphasis not only at the child as an actor in its own media consumption but also a shift towards focusing on the contextual role of the family and parents in the influence that media can assert on younger children. Within this line of research it is highlighted that the parents not only select out harmful media content, but also promotes the child's ability to interpret and critically review media messages [8]. Internationally the field of Media Literacy, grasp the contemporary changes in the media landscape, and expand the knowledge on how to enhance children to become critical media consumers. This research also deal with the lack of symmetry in the effects imposed by media in terms of not only looking singlehandedly on risks, but also taking opportunities like the development of creativity, identity and civic participation into consideration when the outcomes of media influence is investigated.
Studies on parental mediation seeks to understand how parents' can prevent their children from harmful media influence and through guidance learn to interpret the visual codes of screen media and let them evolve into critical media consumers. In this process the age of the child [1] as well as factors in the family setting like the socio-economic resources of the parents' $[9,10]$ and the lifestyle of the family $[11,12]$ are known to influence mediation. However, parental mediation is not exclusively explained by socio-demographic factors. Previous research has shown that attitudes toward the media also influence parental mediation. Parents' with highly negative attitudes towards television are more likely to engage in all types of mediation [13,14] especially restrictive mediation, using rules on media usage [1]. Some studies have also shown that mediation is more prevalent among parents who believe strongly in the effects of televisions on children $[1,8]$.

Focus in this paper is on the relation between the parents' perceptions of media influences on preschool children (2-5 year olds) and two types of parental mediation-co-viewing/using and instructive mediation-concerning three different kind of media types-television (TV), TV-/computer games and the Internet. Three questions are posed:

Q1) What perceptions of media influence do the parents to children aged 2-5 years old have and how do these perceptions relate to each other depending on different media types? Q2) To what extent do parents co-view/-use different kind of media and use instructive mediation together with their child/children depending on different media types? Q3) Do we co-view/use media and use instructive mediation more if we

*Corresponding author: Gabriella Sandstig, Department of Journalism, University of Gothenburg, Gothenburg, Sweden, E-mail: Gabriella.Sandstig@jmg.gu.se

Received September 26, 2013; Accepted October 16, 2013; Published October 24, 2013

Citation: Sandstig G (2013) The Influence of Parental Perceptions of Media Influences on Co-viewing/using Media and Instructive Mediation with Younger Children. J Mass Communicat Journalism 3: 163. doi:10.4172/2165-7912.1000163

Copyright: ( 2013 Sandstig G. This is an open-access article distributed under the terms of the Creative Commons Attribution License, which permits unrestricted use, distribution, and reproduction in any medium, provided the original author and source are credited. 
are positive towards the effects of different kind of media than if we are negative towards media influences or is it the other way around?

\section{The influence of the parents perceptions towards media,} media content and media influence

If the parents have highly negative attitude towards media and media content, and they are parents to younger children the probability that they will mediate and use restrictive mediation rather than instructive or active mediation is higher than for the parents of older children. Several studies identified that parents with highly negative attitudes toward television are more likely to engage in all types of mediation (Warren, 2005:848) especially restrictive mediation (ibid: 860 ). Restrictive mediation is also the primary mediation type for 3-5 year old children [1]. The amount of mediation is on the one hand related to the age of the child and on the other to the engagement of the parent. Several studies have showed that the younger the child the higher the amount of mediation and the more engaged (defined as shared participation in general categories of activities e.g., recreation, home projects, and private talks) the parent, the higher frequency of viewing mediation [1].

But both positive as well as negative attitudes towards the media can contribute to the children becoming critical media consumers. If parents have positive views towards the media and content they are more likely to allow the children more screening time [8], leading to more involvement with the child, and not only predicting the use of restrictive mediation but also instructive. In the study above of 1-5 year olds Becker's (1981) theory of parent-child relations was used to frame mediation in terms of parenting resources [1]. If the parents' attitudes towards media and media content are negative or sceptical they can benefit the evolvement of critical media consumers through their discussions with the child and through fostering critical thinking. Through the use of Bandura's social learning theory (1986) parent's televised viewing of news, co-viewing and positive mediation through reinforced discussion or the combination with a sceptical attitude towards televised news foster critical thinking rather than trust towards the news media that show indirect positive effects on political socialization [9]. In another study the evolvement of mediation strategies by the parents to handle the form of violent content was examined. The children (5-12 years) were asked to consider the program's reality status and the strategies that developed emphasized the program as either factually inaccurate or socially unrealistic [14].

From research on parental mediation we also know that viewing rules and co-viewing are more prevalent among parents who believe strongly in televisions effects on children [1]. A study of parents' views on media influence, show that 99 percent of the parents believed that popular media (cartoons and violent video games) have either short- or long-term effects on preschool children [8]. In this study it is therefore expected that parents do believe that media influences their child/ children.

\section{Parental mediation as co-viewing and instructive mediation}

Parents' can assert influence through acting as moderators and enhance salubrious effects of television and mitigate the harmful health effects [15]. A more elaborated answer is that parents can assert influence through their: attitudes towards the media, media content or media influences; involvement in their children's media habits (parental mediation) or own behaviours (media routines or active choices); material and cultural resources.

Mediation can explain how parents directly can prevent their children from harmful media influence. But also how the parents in the long run can prevent their children from media influences through guiding them how to interpret the visual codes of screen media, and let them evolve into critical media consumers. Mediation is often characterized by being one of three types: restrictive mediation, coviewing and instructive mediation. Restrictive mediation includes rules on media usage (amount of viewing time, permissible or forbidden types of content) and using rewards or punishments surrounding the enforcement of such rules [1]. Co-viewing includes a shared set of motivations for viewing (out of common interest, fun or as a coincidental activity [1]. In co-viewing the children's viewing was determined by parents' program selection (ibid). Instructive mediation [1] also known as restrictive guidance or active mediation [16] is an effort to discuss television content in terms children can understand. In this study the influence of the parents' perception of media influence is limited to two types of parental mediation: co-viewing/use and instructive mediation.

\section{Method and Material Used}

The study is based on data from a cross-sectional population survey in Sweden 2010 performed by the the Swedish Media Council, a government agency with the primary task to promote the empowering of minors as conscious media users and to protect them from harmful media influences. Random samples of about 2000 children aged 2-9 years were drawn from the national population register at the Swedish Enforcement Administration and the parent who was most familiar with the child's situation was asked to fill in the questionnaire together with the child if possible. 1195 forms were completed with a response rate of $62 \%$ among the parents to child/children aged 2-5, and 59\% among the parents to children aged 5-9. An analysis of the non-respondents was made were no differences between respondents and non-respondents was found.

The survey questions asked to determine parental mediation in terms of co-viewing/use was the following: Approximately, how often are you together with the child when he/she...? Answer with one cross on each row. The question asked to determine parental mediation in terms of instructive mediation was: Do you and the child talk about what he/she...? The alternative activities to both questions were: Watching tv/dvd; Playing computer/tv-games; Using the Internet; Using the mobile phone. The alternative answers to both questions were: Often; Sometimes; Occasionally: Never; The child does not use; Don't know.

The survey question asked to determine the parents' perceptions of media influence on their child/children were: Here are some claims about [one of the media: tv, computer/tv-games and the internet]. Cross the claims that you agree on. The alternative claims were: Makes the child learns good things; Makes the child learns bad things; Makes the child passive; Is a way to socialize; Is addictive; Stimulates the child's imagination; Is a waste of time; Leads to ill health; Is fun and relaxing; Makes the child aggressive. The statistical analysis was performed using the SPSS 20.0 Software package.

\section{The Parents Perceptions of Media Influences on their 2-5 years old child/children}

In this section a factor analysis based on the 10 available answers in the survey by the Swedish Media Council 2010 is conducted. Depending on the media type the analysis falls out in two or three dimensions. The first dimension concerns negative aspects of media influences, meaning classical effects research topics. The second dimension constitutes more or less of positive aspects of media influences, while the third dimension is more of a mix between positive and negative outcomes. These factors or dimensions have then been used as the basis for creating a modest 
Citation: Sandstig G (2013) The Influence of Parental Perceptions of Media Influences on Co-viewing/using Media and Instructive Mediation with Younger Children. J Mass Communicat Journalism 3: 163. doi:10.4172/2165-7912.1000163

Page 3 of 5

additive index to use in the elaboration of how the parents perceptions of media influences correlate with co-viewing/using and instructive mediation concerning different media types.

Comments: The factor analysis included the 10 available alternative answers in the 'Medierådet' Survey 2011. Extraction method: Principal Component Analysis. Rotation Method: Varimax with Kaiser Normalization. Maximum cumulative explained variance: TV: $22 \%$; Games: $28 \%$ and Internet: $31 \%$. It is not possible to set max 2 iterations on TV or Internet. The correlations between the negative consequences are stronger than between the positive. It is also more common among the parents to have perceived at least one of the positive consequences than one of the negative or mixed.Only a limited share of the parents has solely perceptions of negative media influences on their children (4-6\% depending on media type). It is more common among the parents to solely have perceptions of positive media influences (25$31 \%$ depending on media type). However the most common among the parents is to have perceptions of both positive and negative media influence on their children (63-71\% depending on media type). In either way there is clear support for that parents' not only have perceptions of negative media influence on their children but also perceptions of positive media influences. The index used for measuring the parents' perceptions of media influence on their child/children is an additive index based on the idea of the three dimensions: positive, negative and mixed from Table 1, that has been complemented with the aspect of to what extent (three or more types) the parents' express perceptions of positive respective negative influence. The perceptions of media influences slightly (statistically significant) vary depending on the generation of the parent but not after gender. The general pattern is that the older generations (born 1946-1964) to a higher extent perceive positive media influences independent of the media types asked for in this study than the younger (born 1977-1994). The pattern among the younger generations is the opposite. The younger generation of parents to a higher extent than the older generations perceives negative media influences on their child/children.

\section{Parental mediation in terms of co-viewing/using media and instructive mediation}

Almost two thirds of the parents often co-view or co-use media with their2-5 year old child/children and more than two thirds of the parents together with the child/children talk about what he or she has seen on film or TV, played on computer or TV-games or have done or experience on the internet (Table 2). There are slight differences between the different types of media. It is more common to sometimes or often co-view films or television and to discuss what the child/children have seen on films or television than it is to play games and discuss games together or do or experience and discuss the web together.

\section{The influence of parental perceptions of media influences on co-viewing/using media and instructive mediation}

Generally the results are that the more perceptions of positive media influence by the parents, the more often they co-view/use media or talk about what they have seen with their child/children aged 2-5 years old (Table 3). Among the parents that chose at least three of the positive consequences of television on their child/children it is almost the double share of parents that often co-view and use instructive mediation than only occasionally or never co-view or talk to their child/children about what they have seen. The pattern is not as obvious for media like playing computer- or tv-games or using the internet. The opposite of perceptions of positive media influences goes for the more parents perceive negative media influences. Here it is more common among the parents that chose at least three of the negative consequences to only occasionally or never to co-view any of the three media types. However the same patterns as described above only comply for instructive mediation when it comes to discussion films and TV and not for discussion games or content or experiences on the web.

\begin{tabular}{|c|c|c|c|c|c|c|c|c|}
\hline \multicolumn{9}{|c|}{ Parents perception of the influence of..... } \\
\hline \multirow[b]{2}{*}{ Consequences Dimensions } & \multicolumn{2}{|c|}{...TV on the child } & \multicolumn{2}{|c|}{...TV-/computer games on the child } & \multicolumn{2}{|c|}{...the on the child } & \multicolumn{2}{|l|}{ internet } \\
\hline & Positive & Negative & Mixed & Positive & Negative & Positive & Negative & Mixed \\
\hline Leads to illness & .68 & .19 & .06 & & .76 & -.04 & & .69 \\
\hline Is a waste of time & .64 & -.25 & .12 & & .70 & -.15 & & .58 \\
\hline Make the child passive & .60 & -.13 & .16 & & .70 & -.02 & & .61 \\
\hline Make the child aggressive & .60 & .05 & -.05 & & .66 & .09 & & .61 \\
\hline Is addictive & .58 & -.16 & .10 & & .61 & .12 & & .64 \\
\hline Makes the child learn bad things & .47 & .39 & -.57 & & .58 & .33 & & .62 \\
\hline Stimulates the child imagination & .07 & .64 & .23 & & -.15 & .73 & & .43 \\
\hline Makes the child learn good things & .19 & .68 & -.44 & & .22 & .69 & & .53 \\
\hline Is fun and relaxing & .00 & .64 & .33 & & -.07 & .68 & & .38 \\
\hline Is a way to socialize & .16 & .46 & .53 & & .02 & .57 & & .43 \\
\hline
\end{tabular}

Table 1: Factor analysis of parents' perceptions of different kinds of media influences and their consequences on their child/children aged $2-5$ years old in three different kinds of media types.

\begin{tabular}{|c|c|c|c|c|c|c|c|c|c|}
\hline \multicolumn{4}{|c|}{ Co-view/use of media } & \multicolumn{6}{|c|}{ Instruction mediation } \\
\hline \multicolumn{10}{|c|}{ How often the parents } \\
\hline \multirow{7}{*}{$\begin{array}{l}\text { Use perental } \\
\text { mediation }\end{array}$} & TV/DVD & Games & Internet & Total & TV/DVD & Games & Internet & Total & \\
\hline & Never & 1 & 8 & 5 & 1 & 1 & 3 & 4 & 1 \\
\hline & Occasionally & 10 & 23 & 16 & 5 & 8 & 12 & 12 & 4 \\
\hline & Sometimes & 48 & 42 & 35 & 37 & 36 & 41 & 33 & 31 \\
\hline & Often & 41 & 27 & 44 & 57 & 55 & 44 & 51 & 64 \\
\hline & Percent & 100 & 100 & 100 & 100 & 100 & 100 & 100 & 100 \\
\hline & $\mathrm{N}$ & 1176 & 913 & 803 & 1180 & 1178 & 906 & 780 & 1179 \\
\hline
\end{tabular}

Table 2: How often the parents' co-view/use media and use instructive mediation together with their child/children aged 2-5 years depending on three different media types. 
Citation: Sandstig G (2013) The Influence of Parental Perceptions of Media Influences on Co-viewing/using Media and Instructive Mediation with Younger Children. J Mass Communicat Journalism 3: 163. doi:10.4172/2165-7912.1000163

Page 4 of 5

\begin{tabular}{|c|c|c|c|c|c|c|c|c|c|}
\hline \multicolumn{10}{|c|}{ Co-viewing/using media } \\
\hline \multirow{2}{*}{$\begin{array}{l}\text { Parental perceptions of } \\
\text { media influence }\end{array}$} & \multicolumn{3}{|c|}{ TV } & \multicolumn{3}{|c|}{ Games } & \multicolumn{3}{|c|}{ Internet } \\
\hline & $\begin{array}{c}\text { Occasionally to } \\
\text { never }\end{array}$ & Sometimes & Often & $\begin{array}{c}\text { Occasionally } \\
\text { to never }\end{array}$ & Sometimes & Often & $\begin{array}{c}\text { Occasionally to } \\
\text { never }\end{array}$ & Sometimes & Often \\
\hline At least three negative & 36 & 24 & 22 & 33 & 26 & 21 & 26 & 19 & 19 \\
\hline Mixed and other & 43 & 40 & 37 & 38 & 44 & 46 & 61 & 57 & 59 \\
\hline At least three positive & 21 & 36 & 41 & 29 & 30 & 33 & 13 & 24 & 22 \\
\hline Percent & 100 & 100 & 100 & 100 & 100 & 100 & 100 & 100 & 100 \\
\hline $\mathrm{N}$ & 72 & 432 & 676 & 72 & 432 & 676 & 72 & 432 & 676 \\
\hline \multicolumn{10}{|c|}{ Instructive mediation } \\
\hline \multirow{2}{*}{$\begin{array}{l}\text { Parental perceptions of } \\
\text { media influence }\end{array}$} & \multicolumn{3}{|c|}{ TV } & \multicolumn{3}{|c|}{ Games } & \multicolumn{3}{|c|}{ Internet } \\
\hline & $\begin{array}{c}\text { Occasionally to } \\
\text { never }\end{array}$ & Sometimes & Often & $\begin{array}{c}\text { Occasionally } \\
\text { to never }\end{array}$ & Sometimes & Often & $\begin{array}{c}\text { Occasionally to } \\
\text { never }\end{array}$ & Sometimes & Often \\
\hline At least three negative & 36 & 23 & 23 & 23 & 24 & 24 & 22 & 22 & 18 \\
\hline Mixed and other & 42 & 42 & 37 & 47 & 47 & 43 & 60 & 60 & 58 \\
\hline At least three positive & 22 & 35 & 40 & 29 & 30 & 33 & 13 & 24 & 22 \\
\hline Percent & 100 & 100 & 100 & 100 & 100 & 100 & 100 & 100 & 100 \\
\hline $\mathrm{N}$ & 60 & 370 & 749 & 60 & 370 & 749 & 60 & 370 & 749 \\
\hline
\end{tabular}

Table 3: Co-viewing/using different media and using instructive mediation with the child/children aged 2-5 years depending on the perceptions of media influences of the parents.

\section{Conclusion}

In this paper the Swedish parents' perceptions of media influences and their consequences on their child/children aged 2-5 years are in focus. We know from previous research that restrictive mediation is the most common form of mediation when it comes to younger children and that instructive mediation is scarcer. We also know that effects studies have focused more on the importance of negative media attitudes for parental mediation than the positive. To elaborate on the importance of both positive and negative media attitudes of the parents for parental mediation three questions were posed. The questions (Q1Q3) and the results (R1-R3) are summarized below:

Q1) What perceptions of media influence do the parents to children aged 2-5 years old have and how do these perceptions relate to each other depending on different media types? R1) The results are that the parents have both positive as well as negative perceptions of media influences. Depending on the media type the factor analysis falls out in two or three dimensions, where the first dimension constitutes of negative aspects of media influences, the second dimension of positive aspects of media influences and the third dimension is more of a mix between positive and negative outcomes. How does the parents perceptions relate to their socio-demographics? The older generations of parents generally to a higher extent perceive positive media influences independent of media type while younger generations of parents generally to a higher extent perceive negative media influences independent of media type.

Q2) To what extent do parents co-view/-use different kind of media and use instructive mediation together with their child/children depending on different media types? R2) In line with previous research it is very common to co-view/use media. But on the contrary to previous research it is even more common to discuss the content and experience with their 2-5 years old child/children. As expected it is most common to co-view films or television but also to discuss what the child/children have seen on films or television.

Q3) Do we co-view/use media and use instructive mediation more if we are positive towards the effects of different kind of media than if we are negative towards media influences or is it the other way around? R3) The more perceptions of positive media influence, the more often we co-view/use media with our child/children aged 2-5 years old. The results are in line with the research by Funk et al. (2009) where parents positive views towards the media and content are more likely to allow the children more screening time, leading to more involvement with the child, and not only predicting the use of restrictive mediation but also instructive.The opposite goes for the more we perceive negative media influences. However the same pattern only complies for instructive mediation when it comes to discussion films and TV, and not for discussion games or content or experiences on the web.

\section{References}

1. Warren R (2003) Parental mediation of preschool children's television viewing Journal of Broadcasting \& Electronic Media 47: 394-417.

2. Lowery SA, DeFleur ML (1995) Milestones in Mass Communication Research, 3rd edn. New York: Longman.

3. Strasburger VC, Wilson BJ, Jordan AB (2009) Children, Adolescents, and the Media. 2nd ed. Thousand Oaks, CA: Sage.

4. Carlsson U (2010) Children and Youth in the Digital Media Culture. Gothenburg Nordicom, University of Gothenburg.

5. Livingstone S, Haddon L (2009) Young People in the European Digital Media Landscape. Gothenburg: Nordicom, University of Gothenburg.

6. Tufte B, Ekström KM (2007) Children, Media and Consumption. Gothenburg Nordicom, University of Gothenburg.

7. vonFeilitzen C, Carlsson U (2007) In Service of Young People? Gothenburg Nordicom, University of Gothenburg.

8. Funk JB, Brouwer J, Curtiss K, McBroom E (2009) Parents of Preschoolers Expert Media Recommendations and Ratings Knowledge, Media-Effects Beliefs, and Monitoring Practices. Pediatrics 123: 981-988.

9. Austin EW, Bolls P, Fujioka Y, Engelbertson J (1999) How and why parents' take on the tube. Journal of Broadcasting \& Electronic Media 43: 175-192.

10. Valkenburg PM, Krcmar M, Peeters AL, Marseille NM (1999) Developing a scale to assess three styles of television mediation: "Instructive mediation," "restrictive mediation," and "social coviewing. Journal of Broadcasting \& Electronic Media 43: 52-66.

11. Atkin DJ, Greenberg BS, Baldwin TF (1991) The Home Ecology of Children's Television Viewing-Parental Mediation and the New Video Environment. Journal of Communication 41: 40-52.

12. Cho $\mathrm{CH}$, Cheon HJ (2005) Children's exposure to negative Internet content Effects of family context. Journal of Broadcasting \& Electronic Media 49: 488509.

13. Austin EW, Pinkleton BE (2001) The role of parental mediation in the political socialization process. Journal of Broadcasting \& Electronic Media 45: 221-240.

14. Nathanson Al, Wilson BJ, McGee J, Sebastian M (2002) Counteracting the 
Citation: Sandstig G (2013) The Influence of Parental Perceptions of Media Influences on Co-viewing/using Media and Instructive Mediation with Younger Children. J Mass Communicat Journalism 3: 163. doi:10.4172/2165-7912.1000163

Page 5 of 5

effects of female stereotypes on television via active mediation. Journal of Communication 52: 922-937.

15. Christakis DA (2009) The effects of infant media usage: what do we know and what should we learn? ActaPaediatrica 98: 8-16.
16. Nathanson Al, Yang MS (2003) The effects of mediation content and form on children's responses to violent television. Human Communication Research 29: 111-134 